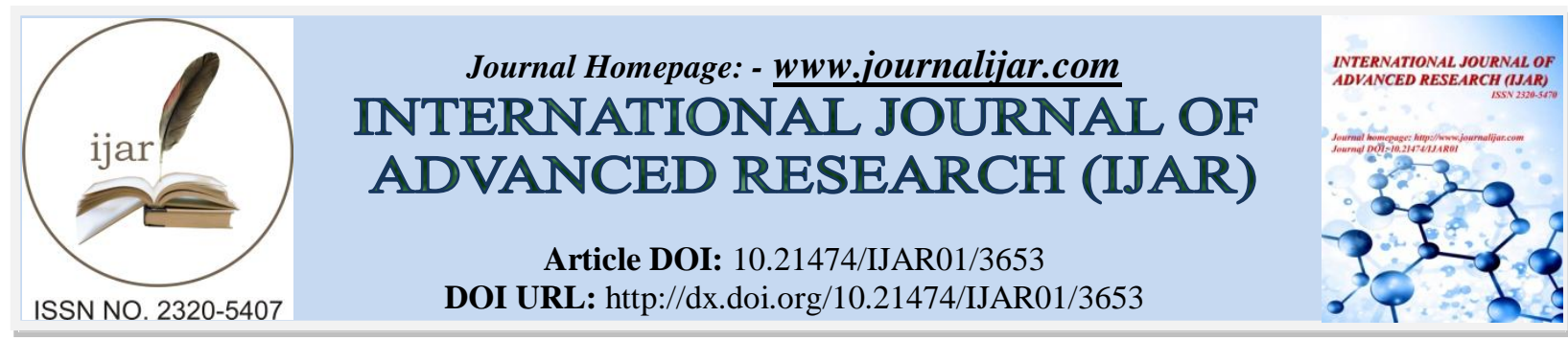

RESEARCH ARTICLE

\title{
CORROSION INHIBITION OF MILD STEEL USING ALOE BARBEDENSIS MILLER SKIN EXTRACT IN 0.5 MHCL.
}

Annie Preetha. M and Dr. Felicia Rajammal Selvarani.

\section{Manuscript Info}

Manuscript History

Received: 10 January 2017

Final Accepted: 02 February 2017

Published: March 2017

Key words:-

Mild Steel Aloe barbedensis

Miller,EDX,EIS

\begin{abstract}
Mild steel is employed widely in most industries due to its low cost and availability in ease for the fabrication of various reaction vessels such as cooling tower tanks, pipelines etc. It can be subjected to aggressive and unfavorable environmental conditions, making it susceptible to corrosion. From the economic and environmental view, plant extracts area $\mathrm{n}$ excellent alternative as inhibitors because of their availability, biodegradability, non toxicity and environmental friendly. The rich source of anthraquinone and other chemical composition of Aloe Vera has been resulted a wide range uses in different sector. The present study deals with the inhibition effect of biodegradable, nontoxicand eco-friendly. Aloe Vera leaf extracton corrosion of mild steel in $\mathrm{HCl}$. The corrosion inhibition of mild steel in the presence of Aloe Barbedensis Miller in $0.5 \mathrm{MHCl}$ was studied by weight loss measurement; electrochemical techniques (Potent iodynamic polarization, A Cimpedance). The maximum efficiency was found to be $81 \%$ at $150 \mathrm{ppm}$. From the result of weight loss studies, the mode of adsorption is found to be physisorption. Kinetic and thermodynamic parameters were calculated and discussed. Potentiodynamic polarization studies indicate that Aloe Barbedensis Miller acts as a mixed type of inhibitor. The surface morphology has been analyzed.
\end{abstract}

Copy Right, IJAR, 2017,. All rights reserved.

\section{Introduction:-}

Corrosion is the destruction of material resulting from an exposure and interaction with the environment. It is a major problem that must be confronted for safety, environmental and economic reasons in various chemicals, mechanical, metallurgical, biomedical and medical engineering applications and more specifically in the design of a much more varied number of mechanical parts. Several efforts have been made using corrosion preventive practices and the use of green corrosion inhibitors is one of them. Natural products have been studied extensively as corrosion inhibitors both in product mixtures extracted from natural sources such as plants or essentially pure products derived from animals or plants (i.e,vitamins and amino acids)[1].From the economic and environmental view points, plant extracts are an excellent alternative as inhibitors because of their availability and biodegradability. These extracts contain a variety of natural products such as essential oils, tannins, pigments, steroids, terpenes, flavones and flavonoids, among other well-known active substances used as CIs.In general, these compounds contain conjugated aromatic structures, long aliphatic chains such as nitrogen, sulfur, and oxygen heteroatoms with free electron pairs that are available to form bonds with the metal surface; in most cases, they act synergistically to exhibit good efficiency regarding the corrosion protection. Aloe Vera is an important medicinal plant which 
belongs to the family of Liliacea. A more recent review concludes that the cumulative evidence supports the use of Aloe barbadensis miller for the healing of first to second degree burns. Aloe Vera plant is used for corrosion protection of metal in acidic medium since it was found for environmental eco-friendly and available in affordable price. The Aloe Vera leaves contain several free anthraquinones and phenolic compounds that aid in absorptive processes in metal surface. The rich source of anthraquinone and other chemical composition of Aloe Vera has been resulted a wide range uses in different sector. In most of the studies related to Aloe Vera gel alone was taken and the outer part of the skin was considered as a waste material. In the present study the outer part of Aloe Vera alone was taken to investigate the inhibitive effect for the corrosion of mild steel in $0.5 \mathrm{M} \mathrm{HCl}$.

\section{Materials and Methods:- Preparation of Mild Steel Specimens:-}

The mild steel samples were obtained from a locally available industrial Fe-C steel with very low concentrationofcarbon.Alargesheetofcoldrolled mild steel coupons have the following chemical composition $0.026 \%$ $\mathrm{Si}, 0.006 \% \mathrm{P}, 0.4 \% \mathrm{Mn}, 0.1 \% \mathrm{C}, 99.4 \% \mathrm{Fe}$. The mild steel samples, with an active surface of $1.2 \times 4.0 \times 0.3 \mathrm{~cm}$ were used for Mass loss measurements and $1 \mathrm{~cm} \times 1 \mathrm{~cm}$ specimen for electrochemical measurements. The mild steel samples were mechanically polished, washed in double distilled water and degreased with acetone and used for the weight loss method and surface examination studies.

\section{Weight - loss method:-}

\section{Determination of Corrosion Rate:-}

Weight loss measurements were carried out using an ACCULAB Electronic balance with readability/sensitivity of $0.1 \mathrm{mg}$ in $210 \mathrm{~g}$ range. The specimens were immersed in beaker containing $100 \mathrm{ml}$ acid solutions without and with different concentration of Aloe Barbedensis Miller leaves extract using hooks. At the end of exposure period, specimens were cleaned according to ASTM G-81 and the weight recorded. The average mass loss of two parallel mild steel specimens was obtained. The test specimens were removed and then washed with de-ionised water, dried and reweighed[2].From the change in weight of specimens the corrosion rate was calculated using the following relationship,

Corrosion Rate $=87.6 \times \mathrm{W} / \mathrm{A} \times \mathrm{T} \times \mathrm{D}(\mathrm{mpy})$

Corrosion Inhibition Efficiency (IE) $\quad \mathrm{IE}=100[1-(\mathrm{W} 2 / \mathrm{W} 1)] \%$

\section{Electrochemical Impedance Spectroscopy:-}

Electrochemical measurements were run using a Potentiostat/galvanostat (Electrochemical system Model Vertex.100mA.D) and a personal computer was used. IVIUM software was used for Electrochemical Impedance Spectroscopy (EIS) and potentiodynamic polarization (PDP) analysis. The EIS measurements were carried out using AC signals of amplitude $10 \mathrm{~m} \quad \mathrm{~V}$ peaks-to-peaks at the open circuitpotentialinthefrequencyrangeof10MHzto1Hz. The charge transfer Resistance ( $\mathrm{R}_{\mathrm{ct}}$ )values have been calculated from the difference in the impedance at low and high frequencies. The capacitances of the double layer $\left(\mathrm{C}_{\mathrm{dl}}\right)$ values are estimated from the frequency(f)atwhichtheimaginarycomponentof the impedance (-Z") is maximum and the double layer capacitance $(\mathrm{C} \mathrm{dl})$ was calculated by using following equation:

Obtained from the equation: $\mathrm{Cdl}=1 / 2 \times 3.14 \times \operatorname{Rct} \times \mathrm{fmax}$

Potentiodynamic Polarization:-

After impedance spectrum was obtained, the potentiodynamic current potential curves was recorded immediately by changing the electrode potential automatically taken from OCP value with scan rate of $5 \mathrm{~m} \mathrm{~V} / \mathrm{S}$ [3].Tafel lines extrapolation method was used for detecting Icorr and Ecorr values for the studied systems.

Scanning Electron Microscope and Energy Dispersive Spectroscopy Analysis:-

For surface morphological study of the uninhibited and inhibited mild steel samples were sent to SEM and EDX analysis[4][5]. 


\section{Results and Discussion:-}

Mass Loss Measurements:-

Effect of Inhibitor Concentration:-

Inhibition efficiency of mild steel with different concentration of Aloe Barbadensis Miller extract in $0.5 \mathrm{M} \mathrm{HCl}$ at room temperature are presented in Table 1.From the table, it is clear that the corrosion rate decreases with an increase in inhibitor concentration, i.e. the corrosion inhibition enhances with the inhibitor concentration. This behavior is due to the fact that the adsorption and coverage of the inhibitor on the mild steel surface increase with the inhibitor concentration. Maximum inhibition efficiency of $81 \%$ was shown at $150 \mathrm{ppm}$ in $0.5 \mathrm{M} \mathrm{HCl}$ at 3 hour immersion, period beyond $200 \mathrm{ppm}$ the system remains constant. The high inhibitive performance of Aloe Barbadensis Miller suggests a higher bonding ability of inhibitor on mild steel surface[6].

Table 1:- Corrosion rate of mild steel in $0.5 \mathrm{M} \mathrm{HCl}$.

\begin{tabular}{|l|l|l|l|l|}
\hline S.no & Concentration $(\mathrm{ppm})$ & Corrosion rate $(\mathrm{mpy})$ & Surface coverage $(\theta)$ & $\%$ I.E \\
\hline 1 & Blank & 18 & - & - \\
\hline 2 & 50 & 6 & 0.66 & 66 \\
\hline 3 & 100 & 5 & 0.72 & 72 \\
\hline 4 & 150 & 3.4 & 0.81 & 81 \\
\hline 5 & 200 & 3.7 & 0.79 & 79 \\
\hline 6 & 250 & 3.6 & 0.80 & 80 \\
\hline 7 & 300 & 3.6 & 0.80 & 80 \\
\hline
\end{tabular}

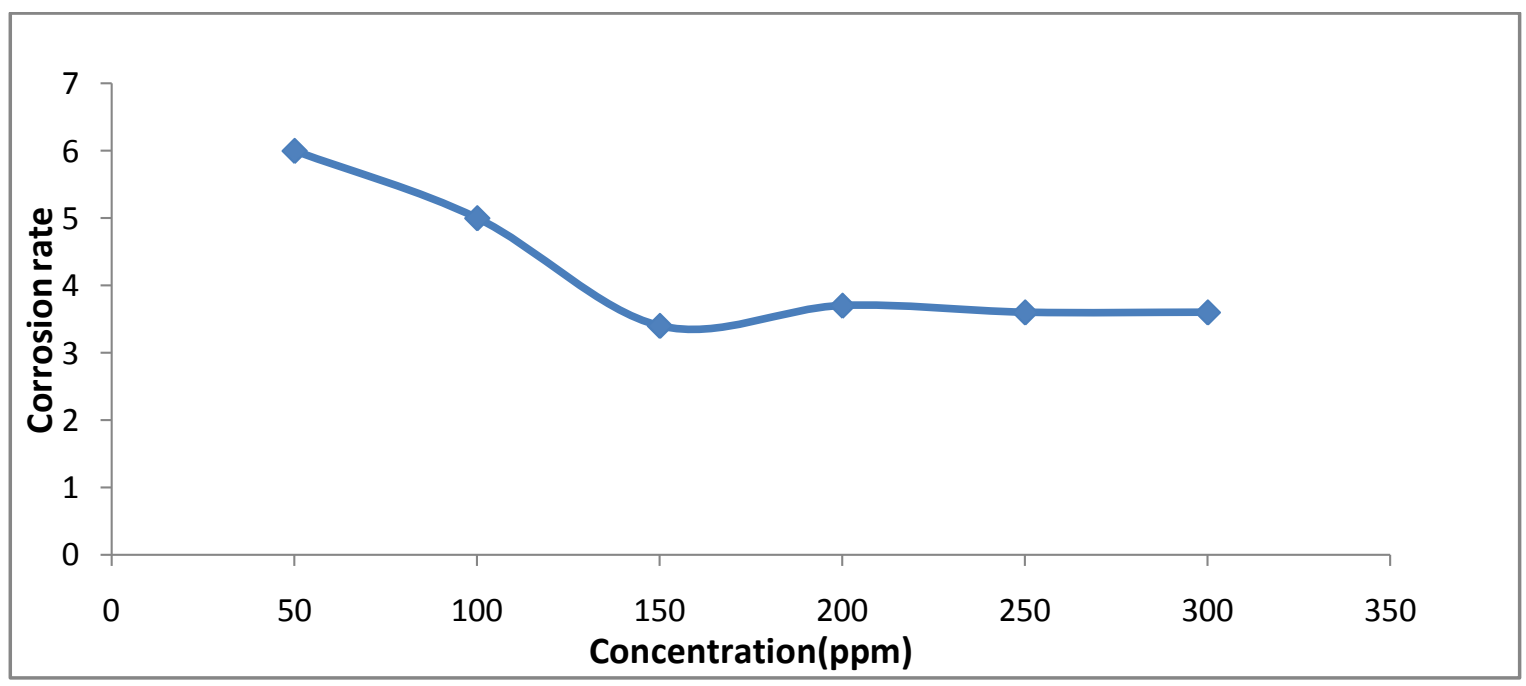

Fig 1:- Corrosion rate of Aloe Barbadensis miller at different concentration. 


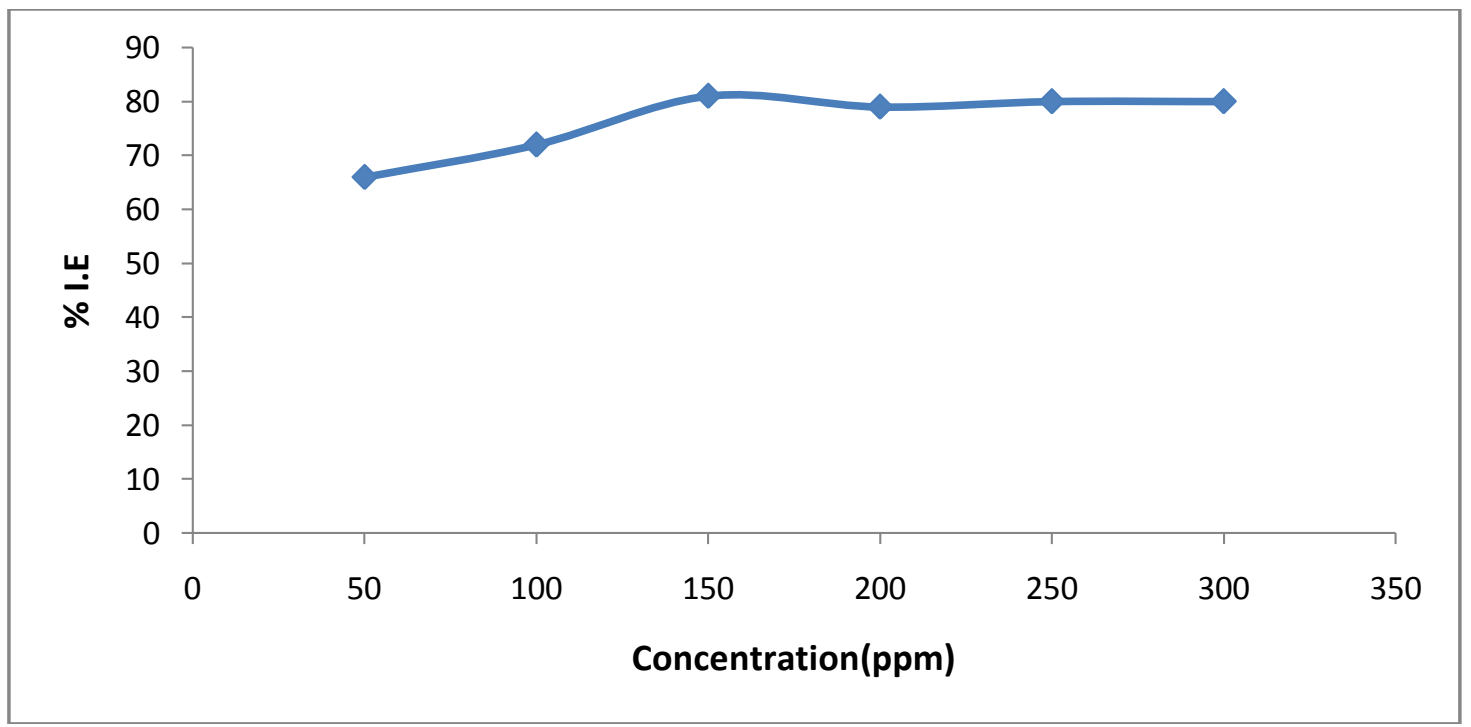

Fig 2:- Inhibition efficiency of Aloe Barbadensis miller at different concentration.

Effect of temperature:-

To show the effect of temperature on inhibition efficiency of Aloe Barbedensis Miller, Weight loss experiment was performed in the temperature range of 308 to $328 \mathrm{~K}$ at optimum concentration. The variation of inhibition efficiency with temperature at optimum concentration are listed in Table 2.From table 2, it is clear that corrosion rate is temperature dependent and increases with increase in temperature[7],[8].

Table 2:- Effect of temperature on the CR of mild in $0.5 \mathrm{M} \mathrm{HCl}$.

\begin{tabular}{|c|c|c|c|c|c|}
\hline S.no & $\begin{array}{c}\text { Temperature } \\
(\mathrm{K})\end{array}$ & $\begin{array}{c}\text { Corrosion } \\
\text { rate(Blank) }\end{array}$ & $\begin{array}{c}\text { Corrosion } \\
\text { rate(Inhibitor) }\end{array}$ & $\begin{array}{c}\text { Surface } \\
\text { coverage }\end{array}$ & $\%$ I.E \\
\hline 1 & 308 & 22 & 5.3 & 0.76 & 76 \\
\hline 2 & 313 & 31 & 9.1 & 0.71 & 71 \\
\hline 3 & 318 & 41 & 10.8 & 0.73 & 73 \\
\hline 4 & 323 & 50 & 15 & 0.70 & 70 \\
\hline 5 & 328 & 75 & 26 & 0.65 & 65 \\
\hline
\end{tabular}

\section{Kinetic and Thermodynamic parameter for corrosion rate:-}

The apparent activation energy $\left(\mathrm{E}_{\mathrm{a}}\right)$, the enthalpy of activation $\left(\Delta \mathrm{H}^{*}\right)$ and entropy of activation $\left(\Delta \mathrm{S}^{*}\right)$ for the corrosion of mild steel in $0.5 \mathrm{M} \mathrm{HCl}$ solution with and without inhibitor at different temperatures are calculated from Arrhenius equation:

$\mathrm{CR}=\mathrm{A} \exp \left(\mathrm{E}_{\mathrm{a}}\right) / \mathrm{RT}$

And from Transition state equation:

$\mathrm{CR}=\mathrm{RT} / \mathrm{hNexp}\left(\Delta \mathbf{S}^{*} / \mathbf{R}\right) \exp \left(-\Delta \mathrm{H}^{*} / \mathrm{RT}\right)$ 


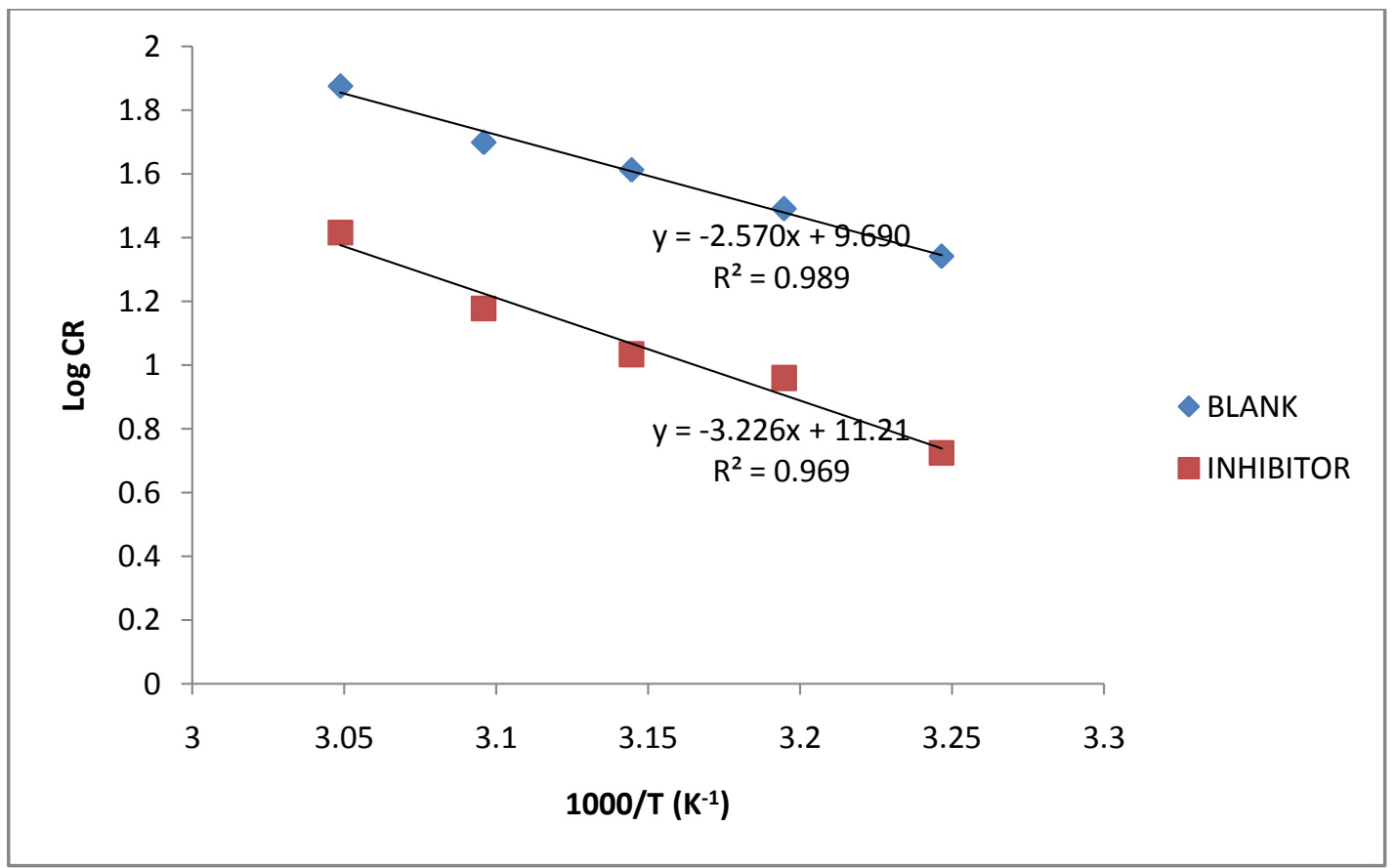

Figure 3:- Arrhenius plots of $\log \mathrm{CR}$ Vs $1000 / \mathrm{T}\left(\mathrm{K}^{-1}\right)$

The Arrhenius plot for mild steel immersed in $0.5 \mathrm{M} \mathrm{HCl}$ with optimum concentration and blank solution is depicted in fig.3.The Activation energy (Ea) is obtained from the slope (-Ea/2.303RT) and the values are listed in table 3.It is evident from the increase in activation energy value in the presence of inhibitor that the reaction undergoes through different mechanism which has a high $\mathrm{E}_{\mathrm{a}}$ value compared to uninhibited system. Hence the rate of corrosion is decreases, as less reactants have that activation energy to reach the activation state.

Table 3:- Thermodynamic parameters for Mild steel in $0.5 \mathrm{M} \mathrm{HCl}$ in the absence and presence of optimum concentration of Aloe Barbadensis Millerleaves.

\begin{tabular}{|c|c|c|c|}
\hline & $\mathrm{E}_{\mathrm{a}}\left(\mathrm{KJmol}^{-1}\right)$ & $\Delta \mathrm{H}^{*}$ & $\Delta \mathrm{S}^{*}$ \\
\hline Blank & 49.21 & 46.5 & -68.18 \\
\hline Inhibitor & 61.7 & 59.12 & -39.07 \\
\hline
\end{tabular}

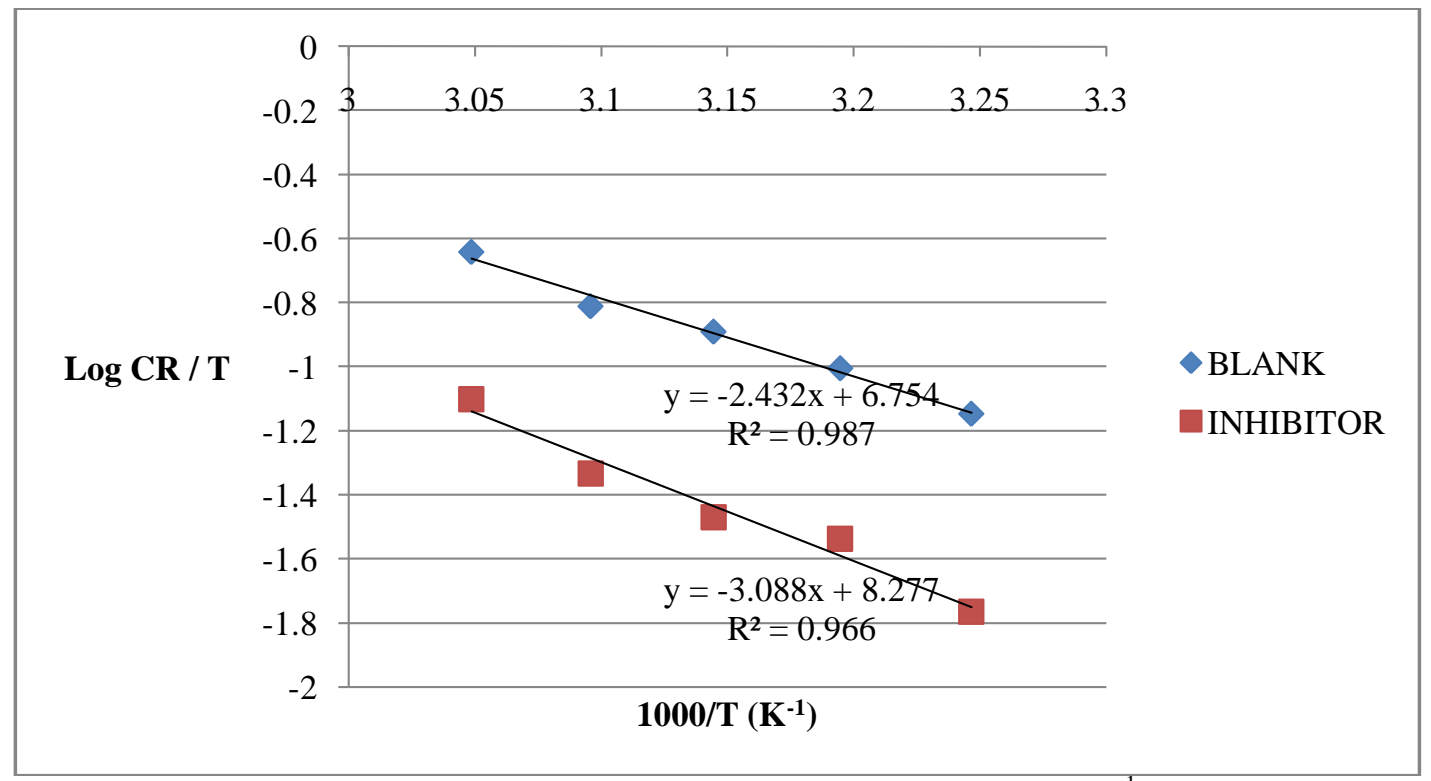

Figure 4:- Transition state plots of Log CR/T Vs 1000/T $\left(\mathrm{K}^{-1}\right)$. 
A plot of $\log (\mathrm{CR} / \mathrm{T})$ Versus $1000 / \mathrm{T}$ is shown in fig.4.Straight lines are obtained with slope $\left(-\Delta \mathrm{H}^{*} / 2.303 \mathrm{R}\right)$ and intercept of $\left[\log (\mathrm{R} / \mathrm{Nh})+\left(\Delta \mathrm{S}^{*} / \mathrm{R}\right)\right]$. The positive value of enthalpy of activation $\left(\Delta \mathrm{H}^{*}\right)$ in the absence and presence of inhibitor at different temperatures reflects the endothermic nature of mild steel dissolution process, which indicates that the dissolution of steel is difficult. It is evident from the table that the value of $\Delta \mathrm{H}^{*}$ increases in the presence of the inhibitor than in the absence. This shows the higher protection efficiency of the inhibitor. This may be attributed to the presence of high energy barrier for the reaction and hence there is rise in enthalpy of the corrosion process.

From Table 3, it is clear that there is an increase in the entropy of activation in the presence of inhibitor system compared to its absence.The large negative value of entropy of activation in the absence of inhibitor shows that it has more ordered arrangement in the transition state whereas in the presence of inhibitor system the entropy of activation becomes less negative showing that the surface of the metal is covered with inhibitor molecules thus moving the system towards less ordered arrangement.

\section{Adsorption Parameter:-}

The primary step in the action of inhibitors in solution is generally agreed to be adsorption on the metal surface. This involves the assumption that the corrosion reactions are prevented from occurring over the area (or active sites) of the metal or alloy surface covered by adsorbed inhibitor species, whereas these corrosion reaction occurred normally on the inhibitor free area. Accordingly, the fraction of surface covered with inhibitor species $(\theta=\% \mathrm{IE} / 100)$ can be followed as a function of inhibitor concentration and solution temperature. The surface coverage $(\theta)$ data are very useful while discussing the adsorption characteristics. When the fraction of surface covered is determined as a function of the concentration at constant temperature, adsorption isotherm could be evaluated at equilibrium condition. The dependence of the fraction of the surface covered $\theta$ on the concentration $\mathrm{C}$ of the inhibitor was tested graphically by fitting it to Langmuir's isotherm, which assumes that the solid surface contains a fixed number of adsorption sites and each site holds one adsorbed species.

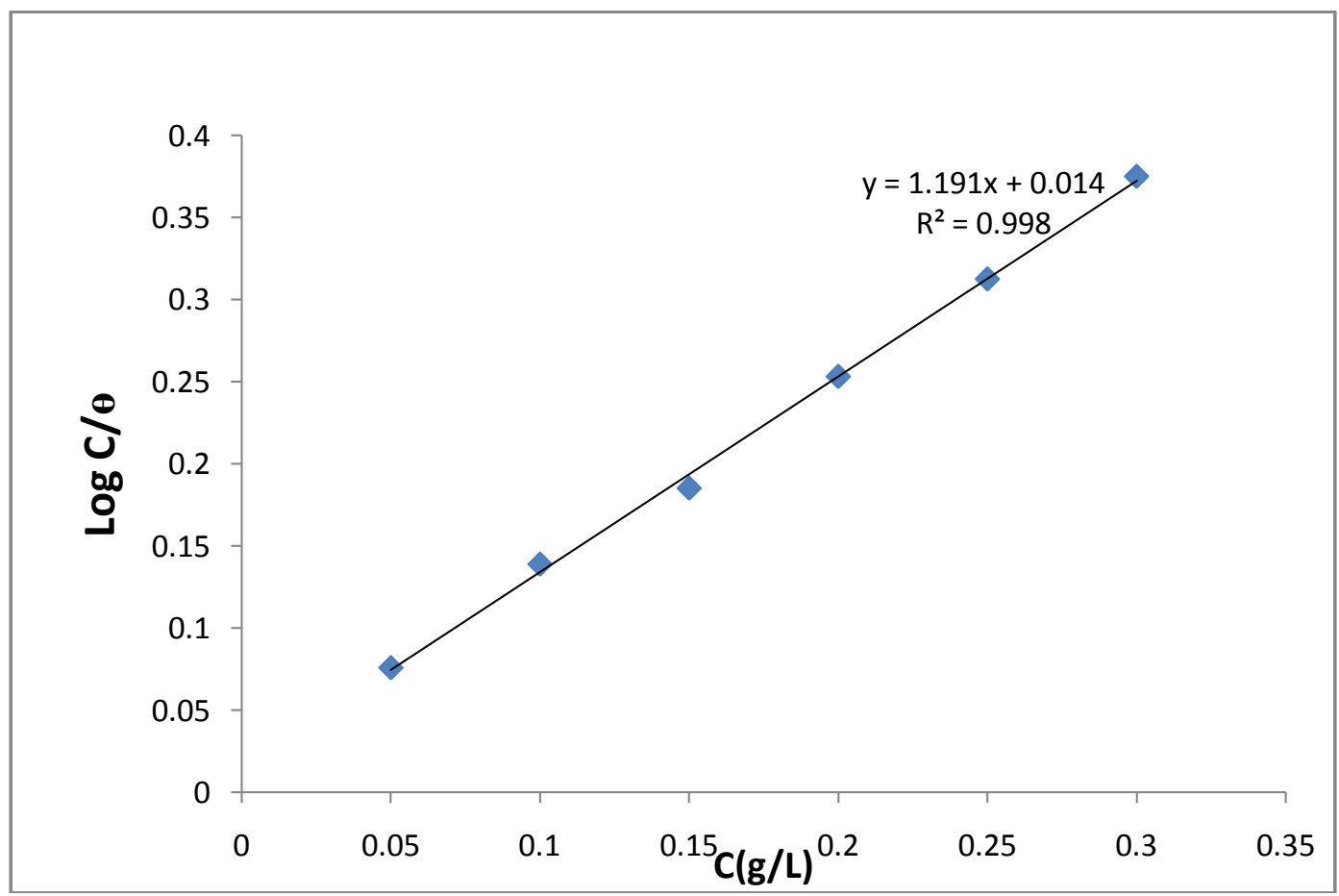

Figure 5:- Langmuir adsorption plot of Log $\mathrm{C} / \Theta$ Versus $\mathrm{C}$.

Table 4:- Langmuir adsorption of Aloe Barbadensis Miller in $0.5 \mathrm{M} \mathrm{HCl}$ on the mild steel.

\begin{tabular}{|l|l|l|l|l|}
\hline Inhibitor & Intercept & $\mathrm{K}_{\mathrm{ads}}$ & $\mathrm{R}^{2}$ & $\Delta \mathrm{G}_{\mathrm{ads}}{ }^{\circ}(\mathrm{KJ} / \mathrm{mol})$ \\
\hline Aloe Barbadensis miller & 0.014 & 71.428 & 0.998 & -10.75 \\
\hline
\end{tabular}

The equilibrium constant for the adsorption process is related to the standard free energy of adsorption by the equation: 


$$
\Delta \mathrm{G}_{\mathrm{ads}}^{\circ}=-\mathrm{RT} \ln \mathrm{K}
$$

The value of $\mathrm{K}$ can be obtained by the following equation $\mathrm{C} / \theta=1 / \mathrm{K}+\mathrm{C}$,

where $\mathrm{C}$ is the concentration of inhibitor ( $\mathrm{g} / \mathrm{lit}), \theta$ is the surface coverage which is given as $\theta=\% \mathrm{IE} / 100 . \mathrm{A} \mathrm{plot}$ of $\mathrm{C} / \theta$ VS $\mathrm{C}$ gives a straight line, from the intercept of the straight line the value of $\mathrm{K}$ can be calculated and the value is substituted in above equation and hence the $\Delta \mathrm{G}^{\circ}$ value is obtained. The negative value of $\Delta \mathrm{G}_{\text {ads }}{ }^{\circ}$ from Table 5 shows that the adsorption process is spontaneous. Normally, the magnitude of $\Delta \mathrm{G}_{\text {ads }}{ }^{\circ}$ around $-20 \mathrm{KJ} / \mathrm{mol}$ or less negative is assumed for electrostatic interactions exist between inhibitor and the charge metal surface(i.e. physisorption). Those around $-40 \mathrm{KJ} / \mathrm{mol}$ or more negative are indication of charge sharing or transferring from organic species to the metal surface to form a coordinate type of metal bond(i.e. chemisorption). The calculated $\Delta \mathrm{G}_{\text {ads }}^{\circ}$ value is -10.75 $\mathrm{KJ} / \mathrm{mol}$ which is less than $-20 \mathrm{KJ} / \mathrm{mol}$ indicates that the adsorption is physical adsorption. The data are also used to study the El-Awady isotherm. The characteristic of the isotherm is given by:

$\log (\theta / 1-\theta)=\log \mathrm{K}+\mathrm{y} \log \mathrm{C}$

Where $\mathrm{C}$ is the concentration of the inhibitor, $\mathrm{\theta}$ is the degree of surface coverage, $\mathrm{K}_{\mathrm{ad}}$ is the equilibrium constant of adsorption process and $\mathrm{K}_{\mathrm{ad}}=\mathrm{K}^{1 / \mathrm{y}}$.

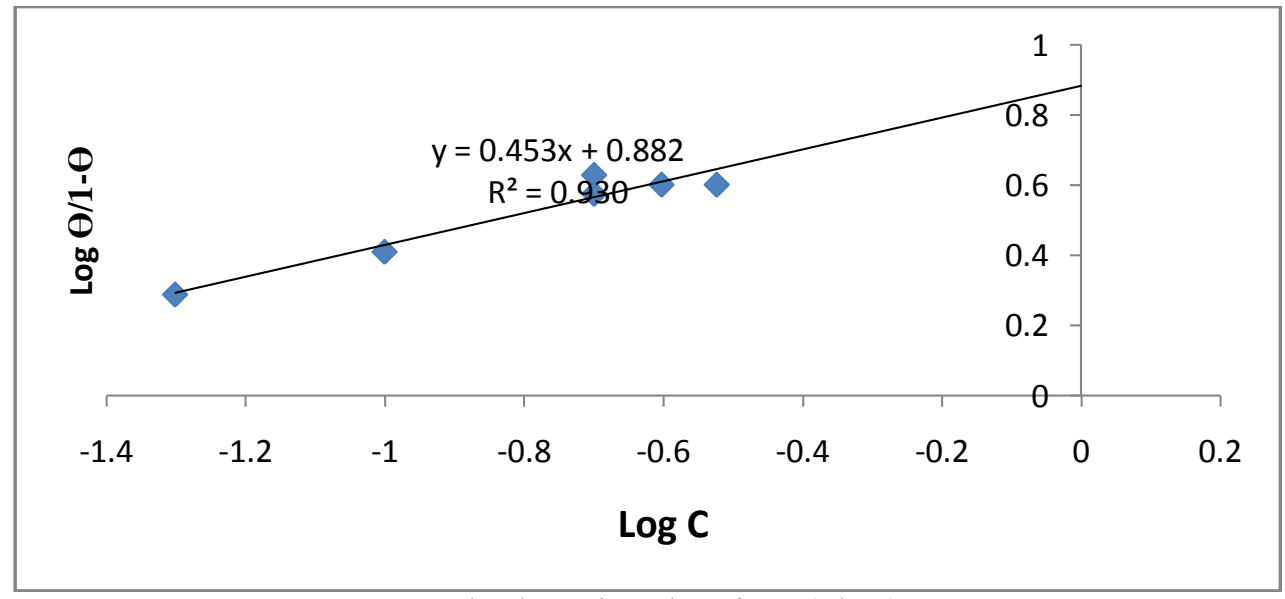

Figure 6:- El-Awadyadsorption plot of $\log (\theta / 1-\theta)$ Versus $\log C$.

Table 5:- El-Awady adsorption of Aloe Barbadensis Miller in $0.5 \mathrm{M} \mathrm{HCl}$ on the mild steel.

\begin{tabular}{|l|l|l|l|l|}
\hline Inhibitor & $\mathrm{K}_{\mathrm{ads}}$ & $1 / \mathrm{y}$ & $\mathrm{R}^{2}$ & $\Delta \mathrm{G}_{\mathrm{ads}}{ }^{\circ}\left(\mathrm{KJ} / \mathrm{mol}^{\circ}\right.$ \\
\hline Aloe Barbadensis miller & 87.09 & 2.207 & 0.930 & -11.25 \\
\hline
\end{tabular}

In this model, the number of active sites $\mathrm{y}$ is included. Values of $1 / \mathrm{y}$ is less than one implies multilayer adsorption, while $1 / y$ greater than one suggests that a given inhibitor molecule occupies more than one active site. Curve fitting of the data to the thermodynamic-kinetic model is shown in fig 6.The plot gives straight line which clearly show that the data fitted well to the isotherm. The value of $1 / y$ and $K_{a d}$ calculated from the El.Awady et.al model curve is given in table 5.It is evident from table.7 that the value of $1 / \mathrm{y}$ is greater than unity showing that the inhibitor molecule occupies more than one active site. The $\Delta \mathrm{G}^{\circ}$ value can be obtained by substituting the value of $\mathrm{K}_{\mathrm{ad}}$ in equation.3.The negative value of $\Delta \mathrm{G}_{\mathrm{ads}}{ }^{\circ}$ from Table.3shows that the adsorption process is spontaneous. The calculated $\Delta \mathrm{G}_{\mathrm{ads}}{ }^{\circ}$ value is $-11.25 \mathrm{KJ} / \mathrm{mol}$ which is less than $-20 \mathrm{KJ} / \mathrm{mol}$ indicates that the adsorption is physical adsorption.

\section{SEM Analysis:-}

The SEM mages were recorded to establish the interaction of inhibitor molecule with metal surface .Figure 7.represents the SEM images of (a) mild steel immersed in $0.5 \mathrm{M} \mathrm{HCl}$, (b) mild steel immersed in the presence of Aloe Barbedensis Miller in $0.5 \mathrm{M} \mathrm{HCl}$ covered with the inhibitors. Result shows that the phytochemical constituents present in the Aloe leaves form a protective layer of the mild steel specimen and thereby reduce the corrosion rate. 

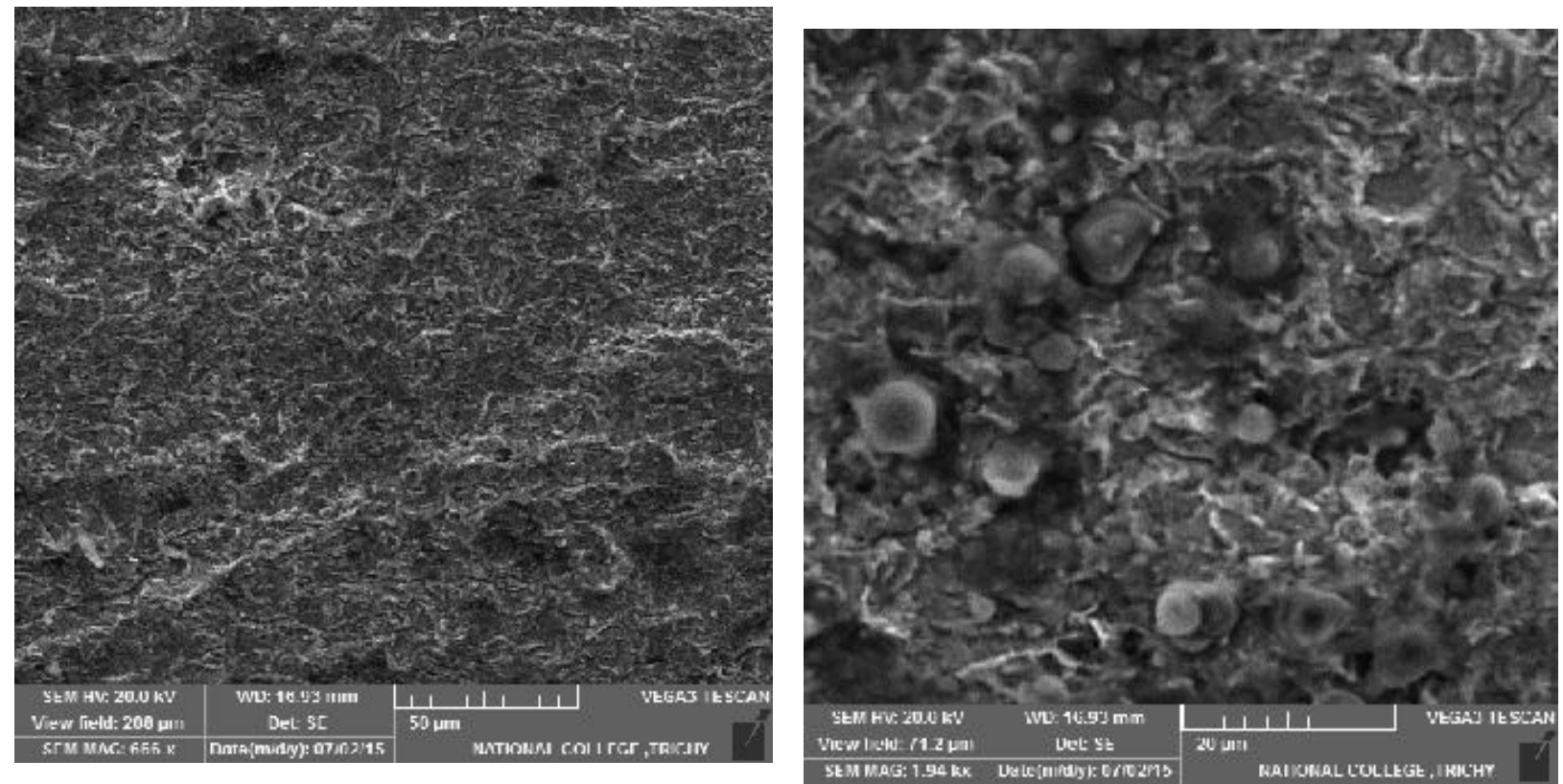

Fig.7:- SEM micrograph of (a) Mild steel immersed in acid (b) Mild steel immersed in the presence of ABMLE in $0.5 \mathrm{M} \mathrm{HCl})$.

\section{Energy Dispersive Spectroscopy:-}

Energy dispersive x-ray analysis (EDX) technique was employed in order to get information about the composition of the surface of the mild steel sample in the absence and presence of the inhibitor in $0.5 \mathrm{M} \mathrm{HCl}$ solution. The EDX spectra of uninhibited and inhibited mild steel samples are shown in fig.8.
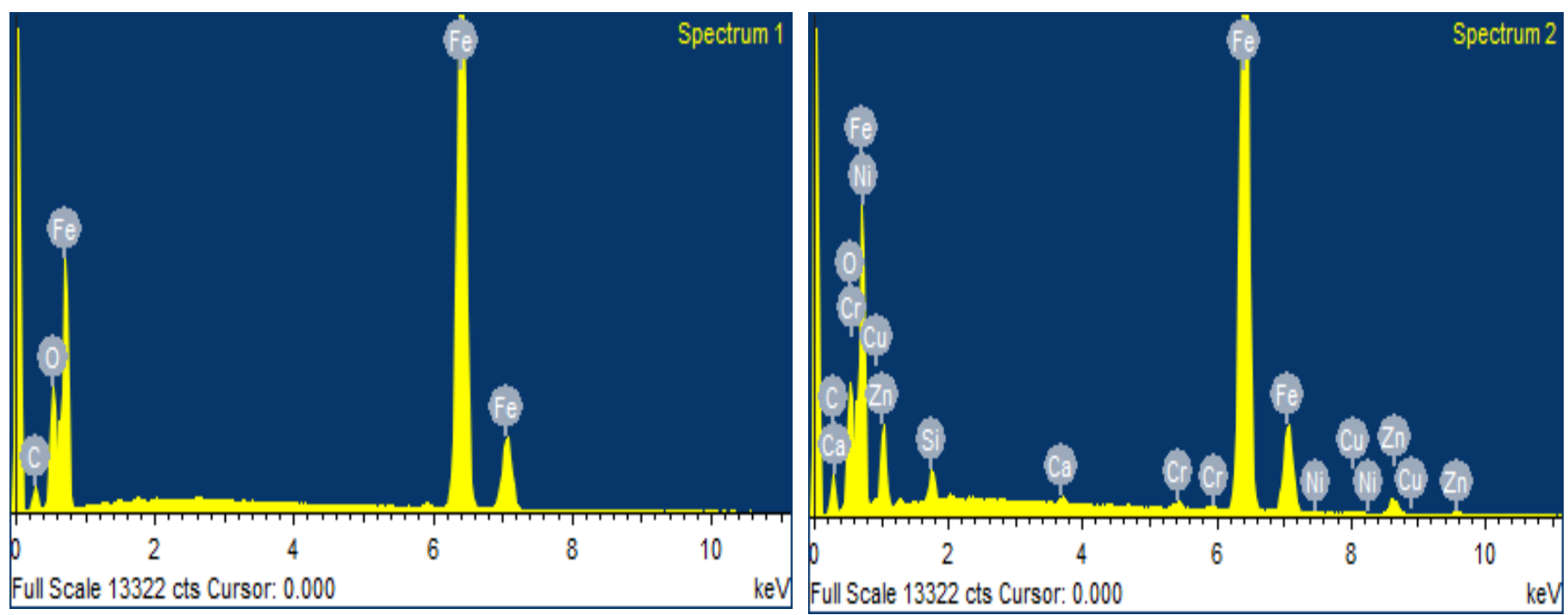

Fig.8:- EDX spectra of mild steel specimens (a) After immersion without inhibitor (b) After immersion with inhibitor.

The percentage atomic content of various elements of the uninhibited and inhibited mild steel surface determined by EDX is listed in table 6.The percentage atomic content of Fe for mild steel immersed in $0.5 \mathrm{M} \mathrm{HCl}$ solution is 79.69 $\%$ and those for mild steel dipped in an optimum concentration of Aloe Barbedensis Miller are 71.96 respectively. From figure 8, the spectra of inhibited samples show that the Fe peaks are considerably suppressed, When compared with the uninhibited mild steel sample. This suppression of Fe lines is due to inhibitory film formed on the mild steel surface. 
Table 6:- .Percentage atomic contents of elements obtained from EDX spectra.

\begin{tabular}{|l|l|l|l|l|l|l|l|l|l|}
\hline Mild steel & $\mathrm{Fe}$ & $\mathrm{C}$ & $\mathrm{O}$ & $\mathrm{Si}$ & $\mathrm{Ca}$ & $\mathrm{Cr}$ & $\mathrm{Ni}$ & $\mathrm{Cu}$ & $\mathrm{Zn}$ \\
\hline Blank & 79.69 & 8.46 & 11.85 & - & - & - & - & - & - \\
\hline Inhibitor & 71.96 & 10.52 & 10.61 & 1.18 & 0.22 & 0.47 & 0.34 & 0.54 & 4.15 \\
\hline
\end{tabular}

\section{Electrochemical Impedance Spectroscopy:-}

In general, as impedance diagrams for solutions examined have almost a semi circular appearance, it indicates that the corrosion of mild steel is mainly controlled by a charge transfer process. The impedance data such as $R_{s}, R_{p}$ and $\mathrm{C}_{\mathrm{dl}}$ were estimated by assuming Randles circuit. The values of charge transfer resistance $\left(\mathrm{R}_{\mathrm{t}}\right)$ and double layer capacitance $\left(\mathrm{C}_{\mathrm{dl}}\right)$ were evaluated from Nyquist and Bode plots. The values of $\mathrm{R}_{\mathrm{t}}, \mathrm{C}_{\mathrm{dl}}$ and \%IE derived from these investigations are given in table 7.The existence of single semicircle showed that single charge transfer process occurred during dissolution of mild steel which is unaffected by the presence of extract. It was found that addition of extract increases the value of $R_{t}$ and reduces the $C_{d l}$ value[9]. The decrease in $C_{d l}$ value attributed to increase in thickness of electrical double layer. The increase in $R_{t}$ value is attributed to the formation of protective film on the metal-solution interface.

Table 7:- The Electrochemical Impedance Parameters of Aloe Barbedensis Miller in $0.5 \mathrm{M} \mathrm{HCl}$ at optimum concentration.

\begin{tabular}{|c|c|c|c|}
\hline System & $\mathrm{R}_{\mathrm{s}}(\Omega)$ & $\mathrm{R}_{\mathrm{ct}}\left(\Omega \mathrm{cm}^{2}\right)$ & $\mathrm{C}_{\mathrm{dl}}\left(\mathrm{F} \mathrm{cm}^{-2}\right)$ \\
\hline Blank & 20.9 & 31.19 & $6.39 \times 10^{-5}$ \\
\hline Inhibitor & 20.31 & 108.3 & $5.780 \times 10^{-5}$ \\
\hline
\end{tabular}

The impedance behavior of mild steel in $0.5 \mathrm{M} \mathrm{HCl}$ in the absence and presence of inhibitor at optimum concentration of Aloe Barbedensis Miller is shown as Nyquist plot in fig. 10 and EIS parameter such as $R_{s}, R_{c t}$ and $\mathrm{C}_{\mathrm{dl}}$ were derived from the Nyquist plot are given Table. 7 The $\omega_{\max }$ represents the frequency at which the imaginary component reaches the maximum. It is the frequency at which the real part $(\mathrm{Zr})$ is midway between the low and high frequency $X$-axis intercepts. It is clear from the result that the value of $R_{c t}$ increases from $31.19 \Omega \mathrm{cm}^{2}$ (Blank) to $108.3 \Omega \mathrm{cm}^{2}$ on the addition of $150 \mathrm{ppm}$ of inhibitor. The value of $\mathrm{C}_{\mathrm{dl}}$ decreases from $6.39 \mathrm{X} 10^{-5} \mathrm{~F} \mathrm{~cm}^{-2}$ (Blank) to $5.780 \times 10^{-5} \mathrm{~F} \mathrm{~cm}^{-2}$. The decrease in capacitance $\left(\mathrm{C}_{\mathrm{dl}}\right)$ on the addition of the inhibitor may be due to increase in the local dielectric constant and /or may be due to increase in the thickness of the double layer,showing that Aloe Barbadensis Miller leaves inhibited Iron metal corrosion by adsorbing at metal/acid interfaces.

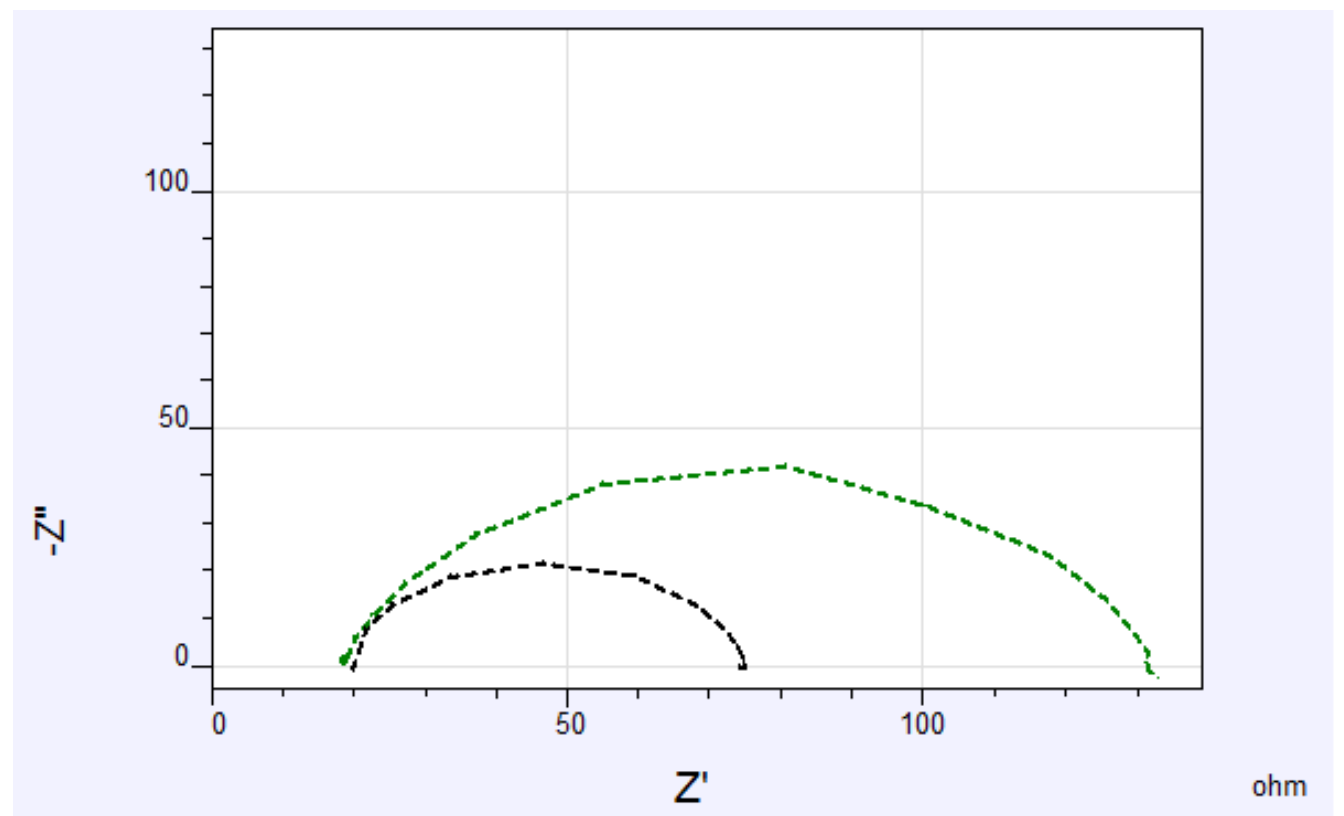

Fig 9:- Nyquist plot in absence and presence of optimum concentration of Aloe Barbadensis Miller. 


\section{Linear Polarization Measurement:-}

The inhibition behavior of Aloe Barbedensis Miller in $0.5 \mathrm{M} \mathrm{HCl}$ in the presence and absence of the inhibitor at optimum concentration are calculated by linear polarization Parameters and are given in Table.8.The efficiency found by linear polarization shows good agreement with efficiency obtained from Tafel and EIS data.

\section{Potentiodynamic Polarization Measurements:-}

The potentiodynamic polarization behavior of mild steel in $0.5 \mathrm{M} \mathrm{HCl}$ in the absence and in the presence of Aloe Barbedensis Miller is shown as Tafel plot in fig. 10 .The various electrochemical potentiodynamic parameters such as corrosion potential $\left(\mathrm{E}_{\text {corr }}\right)$,corrosion current density $\left(\mathrm{I}_{\text {corr }}\right)$, anodicand cathodic slope $\left(\beta_{\mathrm{a}}\right.$ and $\left.\beta_{\mathrm{c}}\right)$ are calculated from Tafel plots and the values are listed in Table.8.It is seen that addition of Aloe Barbedensis Miller decreases the corrosion current $\left(\mathrm{I}_{\text {corr }}\right)$ density from 420.9 (Blank) to $101.8 \mu \mathrm{A} \mathrm{cm}^{-2}$ and shifts the $\mathrm{E}_{\text {corr }}$ from -426.8 to $-396.8 \mathrm{~m} \mathrm{~V}$ SCE. Even though the slight shift of $\mathrm{E}_{\text {corr }}$ to less negative side makes one to think it as anodic inhibitor, but the large shift in the cathodic slope points to the control of cathodic process. Hence it is a mixed inhibitor controlling both cathodic and anodic process.

Table 8:- The potentiodynamic polarization and linear polarization parameters of Aloe Barbadensis Miller.

\begin{tabular}{|l|l|l|l|l|l|}
\hline System & $\begin{array}{l}\mathrm{E}_{\text {corr }} \\
(\mathrm{m} \mathrm{V} / \mathrm{SCE})\end{array}$ & $\begin{array}{l}\mathrm{I}_{\text {corr }} \\
(\mu \mathrm{A} \mathrm{cm})^{-2}\end{array}$ & $\begin{array}{l}\beta_{\mathrm{a}} \\
(\mathrm{m} \mathrm{V} / \mathrm{dec})\end{array}$ & $\beta_{\mathrm{c}}$ & $\mathrm{R}_{\mathrm{p}}$ \\
\hline Blank & -426.8 & 420 & 987 & 1023 & 51.6 \\
\hline Inhibitor & -396.8 & 101 & 985 & 629 & 213.2 \\
\hline
\end{tabular}

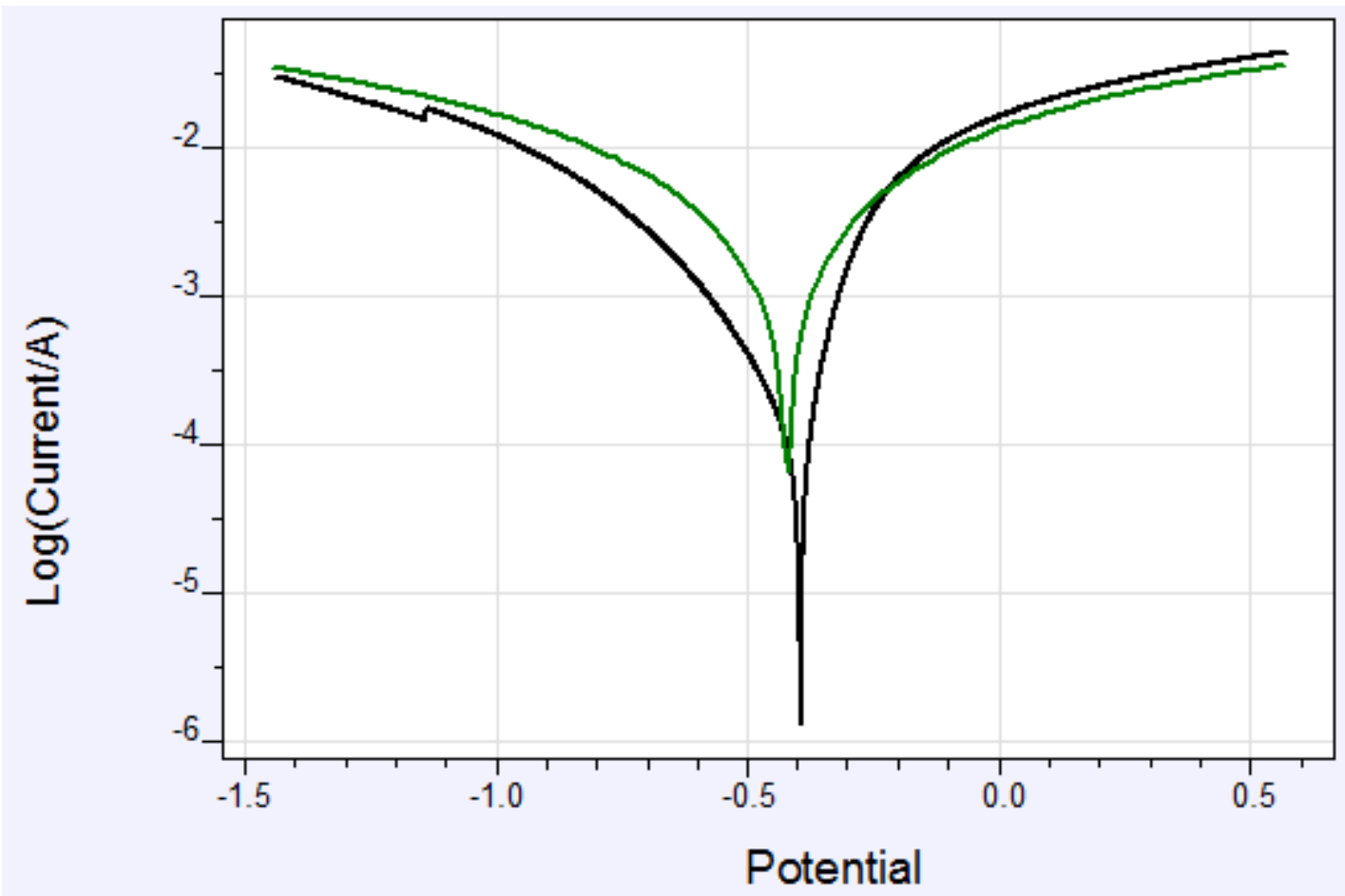

Fig10:-Tafel polarization curves for corrosion product of mild steel in $0.5 \mathrm{M} \mathrm{HCl}$ in the absence and presence of

\section{Conclusion:-}

Aloe Barbadensis Miller.

Aloe Barbadensis Miller skin is good corrosion inhibitors for corrosion of mild steel in $0.5 \mathrm{M} \mathrm{HCl}$ solution.Themaximumefficiencywasfoundtobe $81 \%$ at $150 \mathrm{ppm}$. The adsorption of Aloe Barbadensis Miller on mild steel surface obeyed the Langmuir and Al-Ewady Isotherm. The potentiodynamic studies reveal that Aloe Barbedensis Miller is a mixed type inhibitor. The negative value of $\Delta \mathrm{G}^{\mathrm{o}}$ shows that adsorptionofAloeBarbadensismilleronmildsteel is a spontaneous process. The increase in $\mathrm{Ea}$ value is proportional 
to the inhibitor concentration, indicating thattheenergybarrierforthecorrosioninteractionis also increased. The results obtained from the Weight loss, electrochemical methods, SEM, EDX suggested that the mechanism of corrosion inhibition is occurring mainly through adsorption process. EIS measurement results indicate that the charge transfer resistance of the mild steel electrode increases and double layer capacitance decreases by increasing the inhibitor concentration, showing the formation of the film. The SEM proves the formation of a film on the surface of the metal.

\section{References:-}

1. Obot IB, Obi-Egbedi NO, Umoren SA, Ebenso EE. Synergistic and Antagonistic Effects of Anions and Ipomoea invulcrata as Green Corrosion Inhibitor for Aluminium Dissolution in Acidic Medium. International Journal of Electrochemical Science 2010;5(7) 994-1007.

2. C.S.Hsuand,F.Mansfeld,Corrosion57(2001)747.

3. Dr.J.D.Talati, Dr.N.H.Joshi, "Materials andcorrosion”,(2004),vol. 31, issue 12,926-933.

4. Severin, Kenneth P., 2004, Energy Dispersive Spectrometry of Common Rock Forming Minerals. Kluwer Academic Publishers, 225 p.- [5] Goldstein, J. (2003) Scanning electron microscopy and x-ray microanalysis. Kluwer Adacemic/Plenum Pulbishers, 689 p.

5. Obot,I.B.,Obi-Egbedi,N,O.,Corrosion Science ,52(2010)198. [7]Rajalakshmi,R.Subjhashini,S.Leelavathi,S., Geethanjali,R.,J.Nepal chem.Soc.,25(2010)29.

6. I.Ahamad,R.Prasad and M.A.Quaraishi, Corrosion .Science. 52(2010)3033.

7. Ashassi-Sorkhabi H,Shaabani B,Seifzadeh D.Effect of some pyrimidinic Schiff bases on corrosion of mild steel in HCl.Electrochem Acta2005;50:3446-52.

8. Bentiss F,Traisnel M,Lagrenee M.The substituted 1,3,4-oxadiazoles:a new class of corrosion inhibitors of mild steel in acidic media.Corr.Sci 2000:42:127-46.

9. R.A.Prabhu,T.V.Venkatesha,A.V.Shanbhag,G.M.Kulkarni,R.G.Kalkhambkar,corrosion.science.50 (2008)3356-3362. 